\title{
Impact of Electrical Harmonics on The Efficiency of Energy Consumption of Air Conditioning Systems
}

\author{
Omar Basoudan Yasser Hegazy \\ Riyadh College of Technology \\ P.O.Box 42826 \\ Riyadh 11551 \\ e-mail : basoudan@
}

\begin{abstract}
Harmonics injected to the power system by various equipments represent a burden on the system. The increase in the r.m.s current and therefore, the power consumption due to harmonics is one of its negative consequences. The identification of harmonic sources, the representation of the harmonics and the analysis of the behavior of the equipments with the existence of the harmonics show that a significant increase in these equipment consumption is due to the harmonics.

The load distribution in Saudi Arabia has indicated that air conditioning consumes about $70 \%$ of the load in residential, commercial and governmental sectors. Therefore, the analysis of the impact of the harmonics on the energy consumption of air conditions can verify the benefit gained by increasing the efficiency of these systems with harmonic damping.

This paper presents the results of the harmonic measurements conducted for different type of air conditions in number of loads. It indicates an increase in the consumption of these system due to harmonics. The results show the degree of the harmonic level and therefore, the effect on the equipment efficiency.
\end{abstract}

\section{Introduction}

The issue of electric power quality has captured the attention of electric engineering researchers in recent years [1]. The factors that define the quality of electrical services include, voltage regulation, voltage flickering, service continuity and harmonic distortion. The assessment of the 


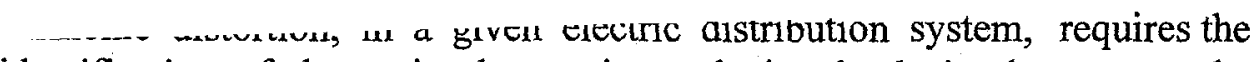
identification of the major harmonic producing loads in that system, the determination of the magnitudes and phase angles of the injected harmonic currents by these loads and the analysis of harmonic propagation in the system $[2,3]$.

The current emphasis on power quality [6] has reinforced the need for harmonic studies as a standard component of distribution system analysis and design. Today, modeling and analysis of distribution systems for harmonic studies have the same level of importance to distribution engineers as voltage drop calculations and loss analysis.

The majority of harmonic studies have been carried out in a deterministic way [3-5]. However, increasing attention has been given to the fact that harmonics produced by several nonlinear loads are subject to random variations, because of fluctuations in their working conditions. Recently, few harmonic analysis studies attempted to address the stochastic nature of these harmonics.

In general, the techniques used to model and simulate the generation and the propagation of harmonics in distribution systems are divided into two main categories. The first category is the deterministic methods, where time domain or frequency domain models are developed to describe the harmonic performance of a certain system. These models are then solved under certain conditions to cover the possible modes of operations of the underlying system. The second category is the probabilistic harmonic analysis methods. These methods deal with the study of the random generation and propagation of harmonics and require different mathematical tools than those of the deterministic methods.

A method was presented to model distribution system loads for probabilistic analysis [7]. This analysis leads to the assessment of the harmonic performance of the system. The method is extended to develop an overall model for the summation of harmonic currents produced by randomly fluctuating loads. The main advantage of the proposed technique are its ability to handle the random variation of harmonics due the random behavior of one of the inherent parameters of the loads and to include the randomness of the load switching process.

On the other hand, the relation between the operation of different load types and the production of harmonics has not been given considerable attention. This paper focuses on the harmonics produced in residential, commercial and governmental sectors buildings. These buildings use about $70 \%$ of the total electrical energy consumed in Saudi Arabia [8]. However, air-conditioning consumes about $70 \%$ of the building energy during summer when the load reaches the peak value $[9,10]$. Hence, any harmonics produced by the air-conditioning systems will have a significant impact on 
the energy consumption. Therefore, reducing harmonics can result in considerable energy savings.

\section{System Measurements}

The harmonic performance of the loads supplied by the Riyadh medium voltage network was investigated. The loads of interest in this network were:

- Commercial loads represented by a shopping mall (Makka mall).

- Educational institutes represented by Riyadh College of Technology.

- Governmental offices represented by King Abdulaziz City for Science and Technology.

- Air Condition loads, different types were included.

In order to obatain general overview of the load performance each of the loads under study was monitored for seven days continously. The measured parameters included, active power (maximum, minimum and average), reactive power, power factor, and both voltage and current harmonic spectra. The summary of the recorded data are presented in Tables 1 to 5 .

\section{Harmonic Measurement Analysis}

The harmonic analysis of the recorded data was performed in order to point out the main harmonic sources in Riyadh city network and to study the effect of the air condition devices upon the harmonic performance of the system. The key findings of this analysis are presented as follows:

Shopping malls have different harmonic patterns during the day. Such a load consists of two main types namely, lighting load and air conditiong load. The actual load of Makka shopping mall was ranging from $4 \mathrm{~A}$ to $104 \mathrm{~A}$ at a medium voltage of $11 \mathrm{KV}$. The corresponding current total harmonic distortion factor $\left(\mathrm{THD}_{\mathrm{i}}\right)$ was ranging from $1.4 \%$ to $17 \%$ Typical harmonic spectrum of 4 different cases of the shopping mall are presented in figure (1). The main reason behind the increase of the harmonic contents of the supply current at light loads is the transformer saturation. Light loads tend to increase the transformer voltage, as a result the transformer goes into its saturation region and the amount of harmonic injected in the system increases.

Both Educational institutes and governmental buildings share the same harmonic characteristics. Their load is mainly flourecent lighting and chiller type air conditions. The harmonic contents associated with these loads are limited and the measured $\left(\mathrm{THD}_{\mathrm{i}}\right)$ is ranging from $0.55 \%$ to $2.4 \%$. However, both the fifth harmonic currents and the third harmonic currents have significant values which might influence the overall performance of the system. 
ine single air conditioning devices are proven to be significant harmonic producing devices. The Window type device operating at $220 \mathrm{~V}$ is injecting both third harmonic currents and fifth harmonic currents with high values. Figure (2) shows the harmonic spectrum of one of these devices. The $\mathrm{THD}_{\mathrm{i}}$ ranges from $7 \%$ during the compressor off period to $30 \%$ when the compressor is on. In addition, the fifth harmonic current reached $29 \%$ during the peak load while the third harmonic current reached $13 \%$ for the same load.

\section{Conclusion}

Air-conditioning systems use a significant percentage of the electrical energy consumed by buildings during summer season, which is a critical time for Riyadh electrical system as the load reaches peak value. The data obtained from the specified loads indicates that air-conditioning is producing significant harmonics in commercial, residential and governmental buildings. The air condition devices used in these buildings and which are producing harmonics are window types and split or small package units. However, large or central air-conditioning using chillers have very limited harmonic contents. Although apartments, shops and other residential and commercial units might find it more economical to use small air-conditioning devices, it is recommended that other measures such as efficiency and energy saving are considered to limit the increase of its energy consumption.

\section{Acknowledgment}

This paper presents part of the outcome of research No. LGP-2-51. The research was funded by King AbdulAziz City for Science and Technology, Riyadh, Saudi Arabia.

\section{References}

1-Daozhi,X., S.Zanxun and Z.Zhenqing "Unified Fundamental Frequency and Characteristic Harmonic Load Flow Solution in AC/DC Power Systems", Proceeding of International Conference on Power System Harmonics, 1989, pp 15-21.

2- Mahmoud,A. and R.D.Shultz, "A Method for Analyzing Harmonic Distribution in A.C Power Systems" IEEE Trans. on PAS, Vol. 101, No. 6, June 1982, pp 1815-1824.

3- Olejniczak,K. and G.T.Heydt, "Basic Mechanisms of Generation and Flow of Harmonic signals in Balanced and Unbalanced Three Phase Power system" IEEE Trans. on PD, Vol. 4, No. 4, October 1989, pp 2162-2170.

4- Richards,G.,G. and H.Yang, " Distribution System Harmonic Worst Case Design Using A Genetic Algorithm." IEEE Trans. on PWRD, SM 1992.

5- Heydt,G,T. "A New Method for the Calculation of Subtransmission and Distribution System Transients Based on FFT", IEEE Trans., on PWRD, Vol 4, No. 3, July 1989, pp 1869-1875. 
6- Fuchs,E.,F., D.J.Roesler and F.S.Alashhab "Sensitivity of Electrical Appliances to harmonics and Fractional Harmonics of the Power System's Voltage." Part I and Part II. IEEE Trans. PWRD, vol 2, No 2, April 1987, pp437-453.

7- Basoudan,O. and Y.Hegazy "Probabilistic Modeling of Distribution System Loads for Harmonic Studies" IEEE PES-2001 summer meeting, 1519 July 2001, Vancouver, Canada.

8- Basoudan,O. and I. O. Almufareji " Electric Energy Consumer Trends Towards Energy Conservation Awarenss Programs" First Saudi Technical Conference, 18-22 November 2000, Riyadh Saudi Arabia.

9- Hasnain, S.M. and M. S. Samiai, "Analysis of Electric Energy Consumption in an Office Building in Saudi Arabia" ASHRAE annual meeting, June 2000, Minnesota, U.S.A.

10- Sabagh, J.A. "Reducing energy consumption and electrical peak load in Saudi Arabia by Reducing Air-Conditioning Load in Buildings" $2^{\text {nd }}$ Symposium on Energy Utilization and Conservation, 27-30 November 1994, Vol. 1, Dhaharan, Saudi Arabia. 

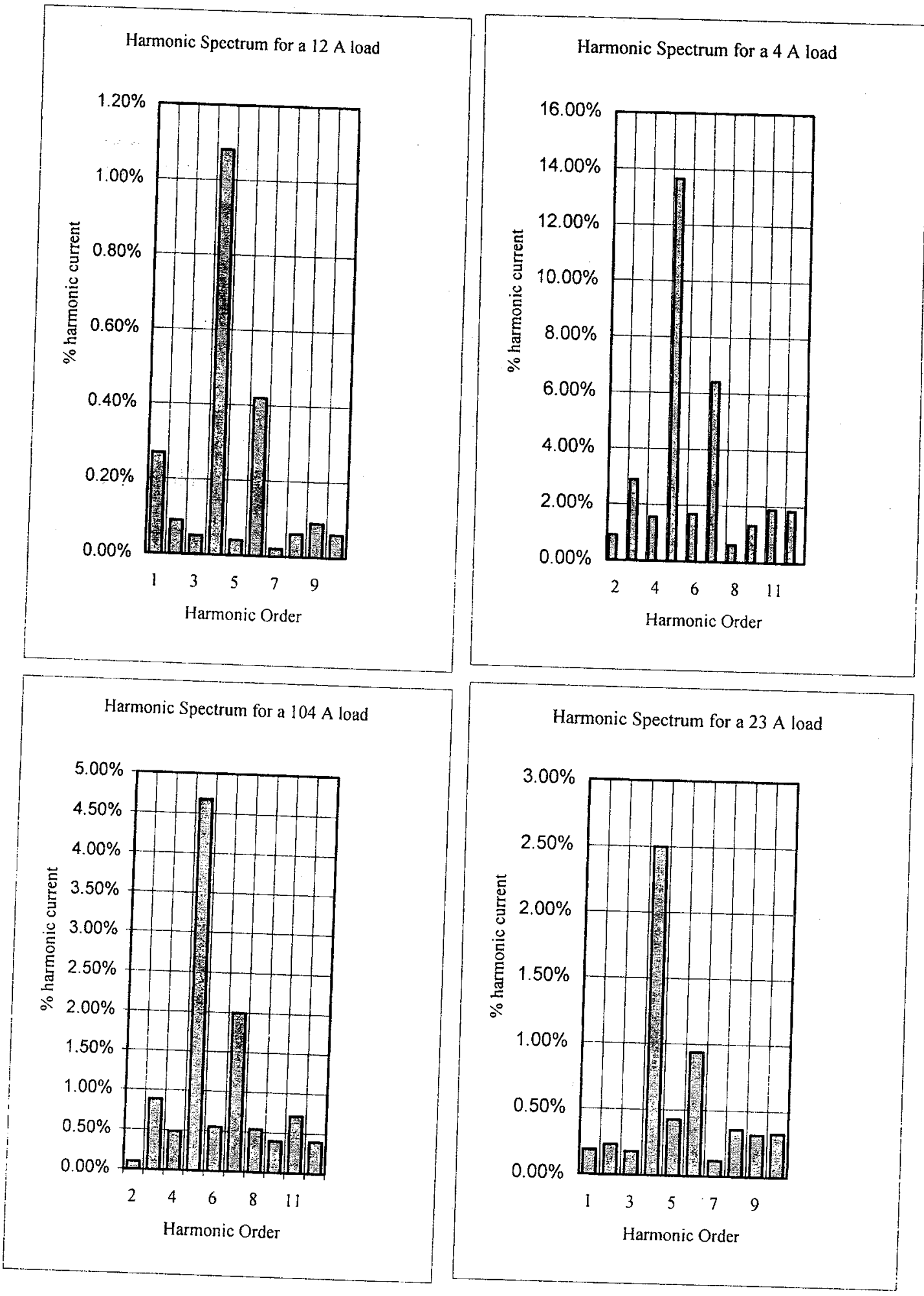

Figure (1) Typical Harmonic Currents Spectrum of The Shopping Mall 

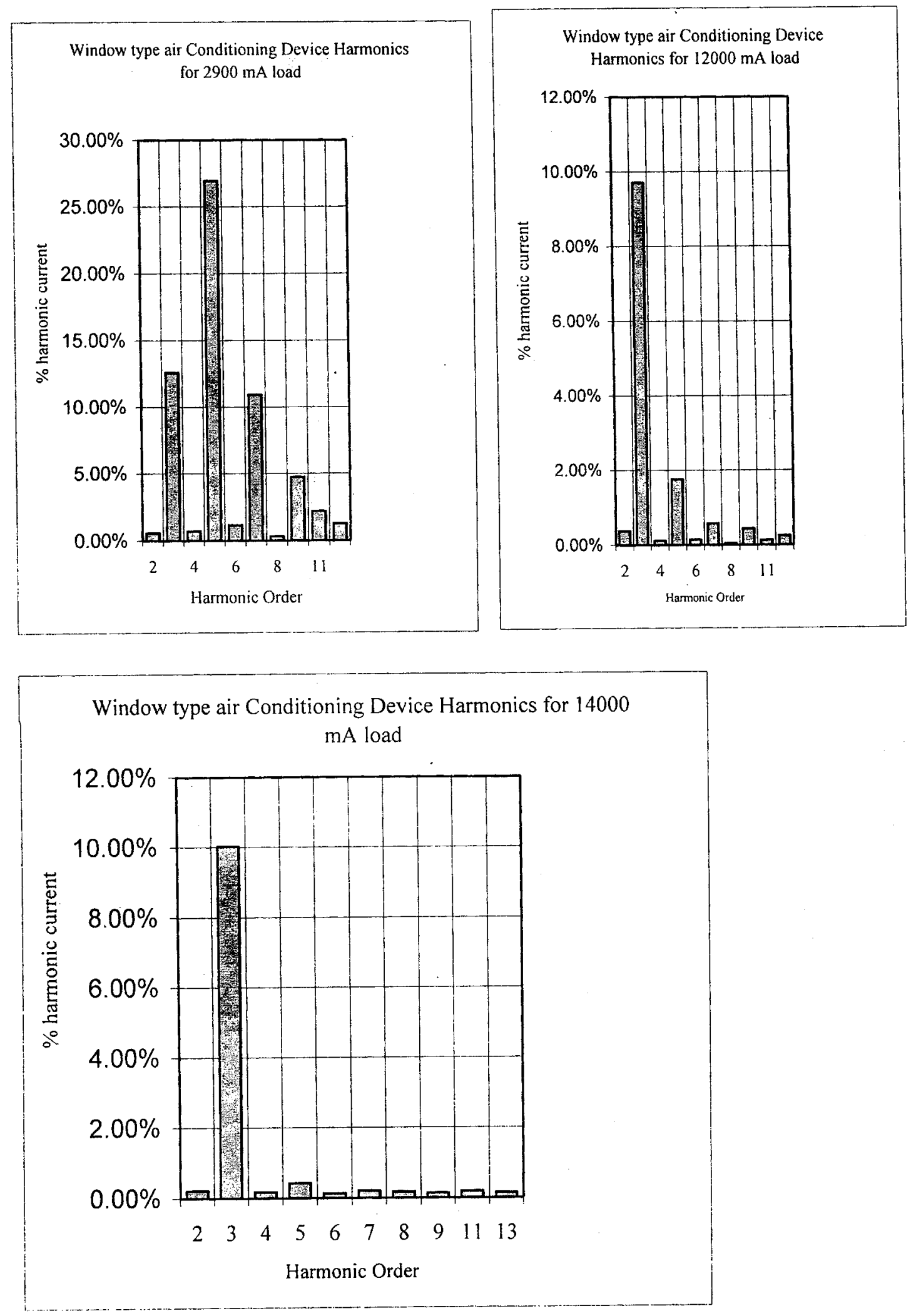

Figure (2) : Typical Harmonic Currents of a Window Type Air Conditioning Device 

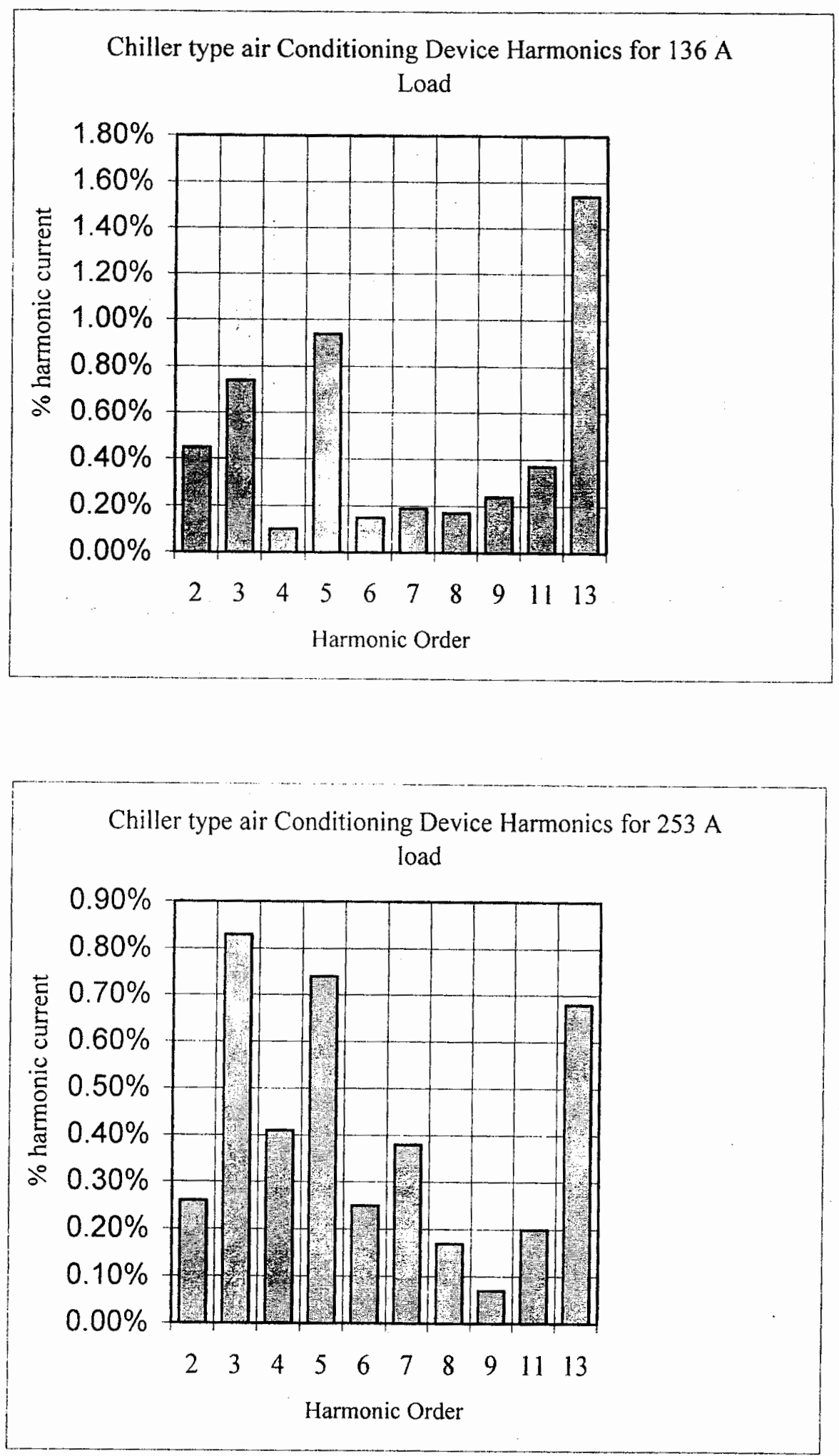

Figure (3) : Typical Harmonic Currents of a Chiller Type Air Conditioning Device 


\begin{tabular}{|c|c|c|c|c|c|c|c|c|}
\hline \multicolumn{2}{|c|}{ Makka Shopping Mall } & \multicolumn{2}{|c|}{ Table (1) } & & & \multicolumn{3}{|c|}{ Page: $67 \quad-d$} \\
\hline E. Name: & & & & & & & Code: : sc14 & $40-d$ \\
\hline No.: & & Prim. S/S & & TEST & From & Fri & \begin{tabular}{|l|l|}
$24-09-99$ \\
\end{tabular} & $8: 00$ \\
\hline Feeder No: & Factor & No.: & & PERIOD & To & Tue & $28-09-99$ & $7: 00$ \\
\hline Reading & MAX & Day & Date & Time & MIN & Day & Date & Time \\
\hline Acrive Power (KW) & 2820 & SAT & $25-09-99$ & $18: 00$ & 66 & SUN & $26-9-99$ & 0.40 \\
\hline Reactive Power (KVAr) & 1723 & SAT & $25-09-99$ & $20: 00$ & 63 & SAT & $25-09-99$ & $4: 40$ \\
\hline Volts (V) $\{7489<V<8+46\}$ & 8053 & MON & $27-09-99$ & $0: 20$ & 7804 & FRU & $24-09-99$ & $18: 00$ \\
\hline Power Factor & 0.86 & FRI & $2409-99$ & $14: 40$ & 0.7 & $\overline{\text { SUN }}$ & $26-09-99$ & $2: 20$ \\
\hline
\end{tabular}

\begin{tabular}{|c|c|c|}
\hline KWh $=106982$ & Average PF $=\cos \left(\tan ^{-1}(\mathrm{KVArh} / \mathrm{KWh})=0.85\right.$ & Metering (Volts) $: 13800$ \\
\hline $\mathrm{KVArh}_{\mathrm{L}}=67526$ & Test Period LF $=$ Adrve engy/(Max adive PWR $\left.{ }^{*}+\mathrm{Hs}\right)=0 .+0$ & AV. ( KW) ) excl. low KW / : 1743 \\
\hline $\mathrm{KVArh}_{\mathrm{C}}=0$ & Rel. WD SPP LF $=$ SPP Aver. KW/Mrx KW $=0.45$ & $\mathrm{~S} / \mathrm{S} \mathrm{MD}$ \\
\hline
\end{tabular}
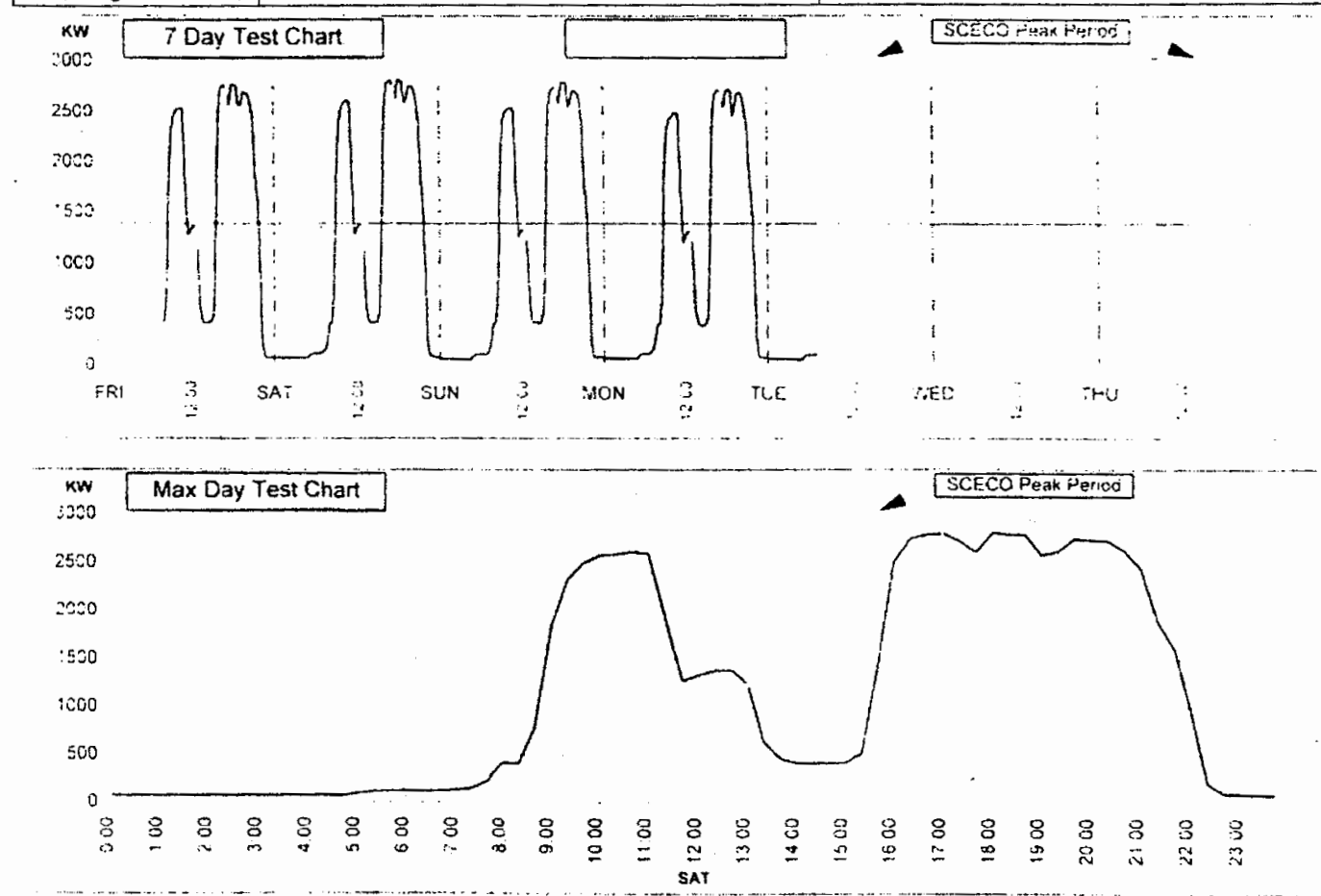

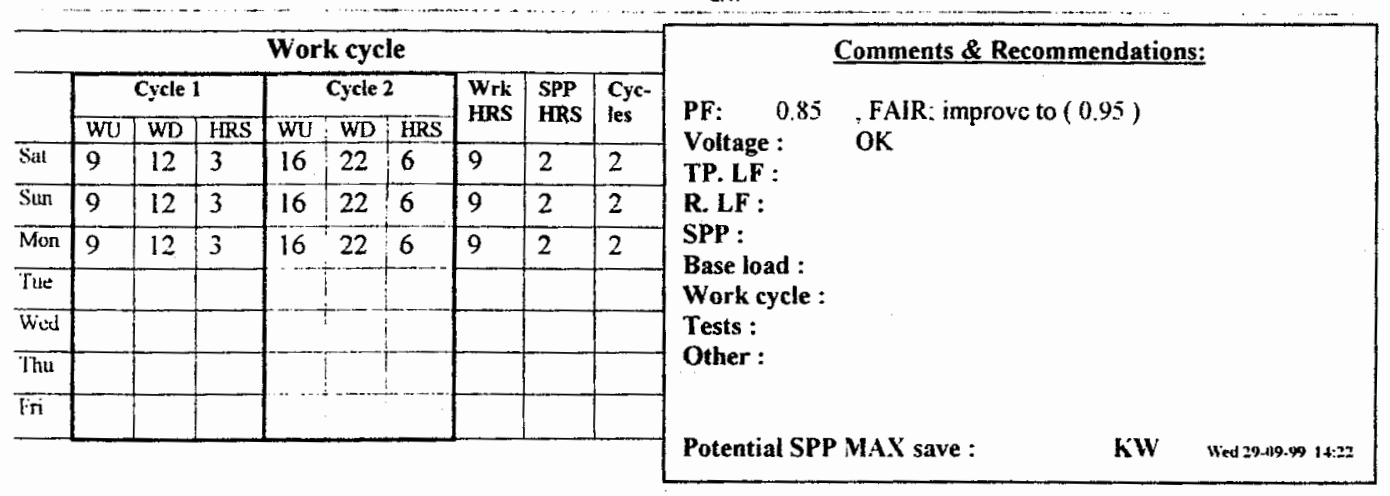




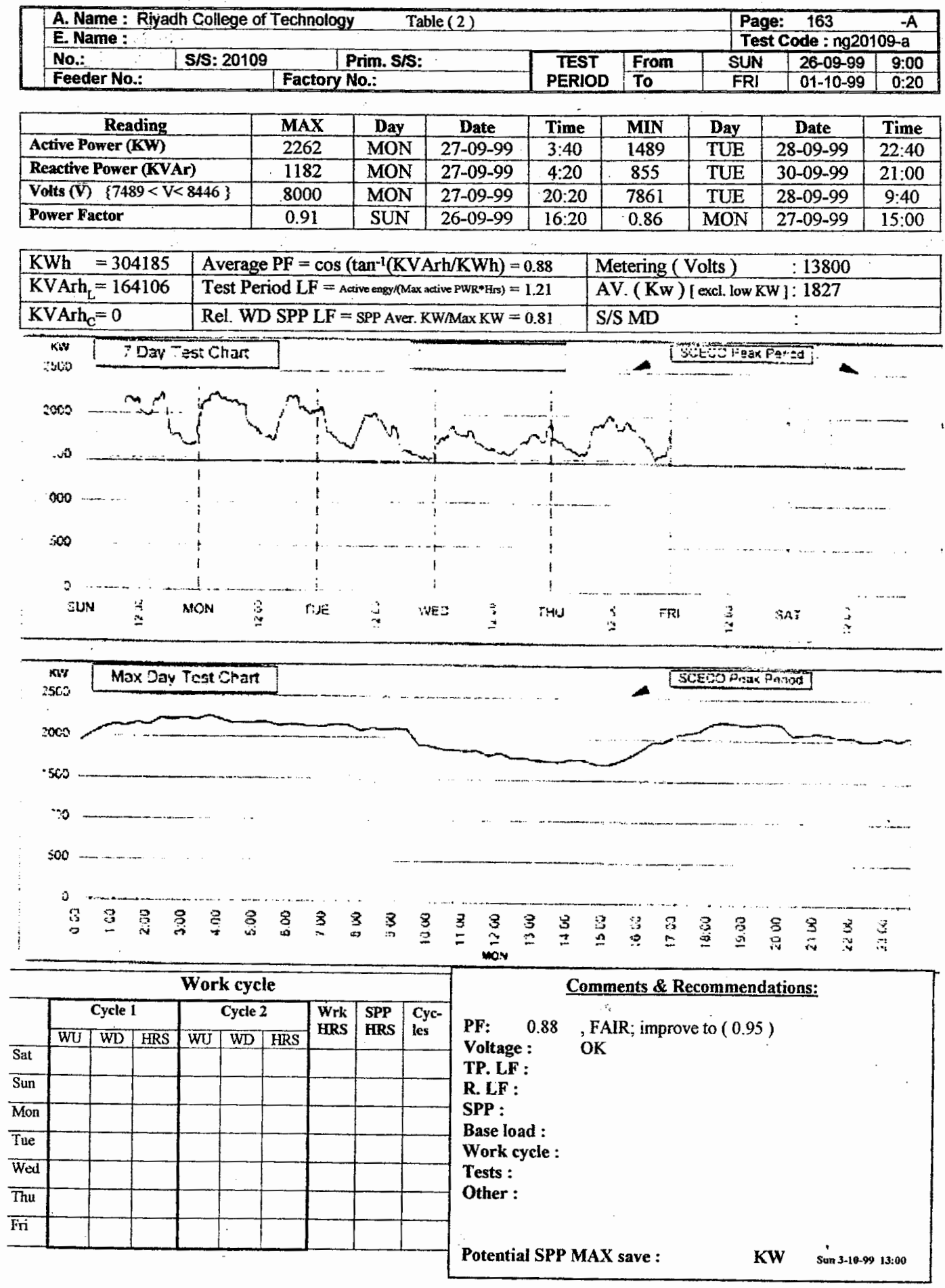




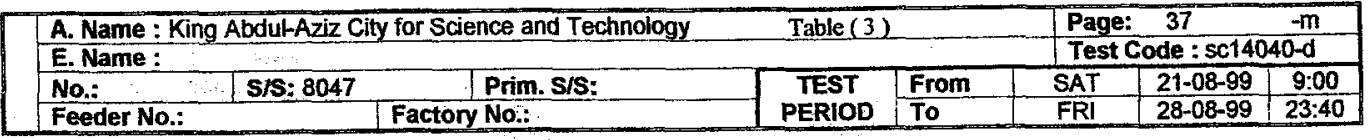

\begin{tabular}{|l|c|c|c|c|c|c|c|c|}
\hline \multicolumn{1}{|c|}{ Reading } & MAX & Day & Date & Time & MIN & Day & Date & Time \\
\hline Active Power(KW) & 8926 & SUN & $22-08-99$ & $12-00$ & 4012 & THU & $26-08-99$ & $5: 40$ \\
\hline Reactive Power (KVAr) & 4388 & SUN & $22-08-99$ & $12: 00$ & 2027 & THU & $26-08-99$ & $5: 40$ \\
\hline $\begin{array}{l}\text { Volts (V) }\{7489<\text { V }<8446 \\
\}\end{array}$ & $\mathbf{8 1 7 6}$ & WED & $25-08-99$ & $14: 20$ & 8045 & SAT & $21-08-99$ & $9: 00$ \\
\hline Power Factor & 0.91 & SUN & $22-08-99$ & $22: 20$ & 0.88 & SUN & $22-08-99$ & $5: 20$ \\
\hline
\end{tabular}

\begin{tabular}{|c|c|c|}
\hline$=935635$ & Average PF $=\cos \left(\tan ^{-1}(\mathrm{KVArh} / \mathrm{KWh})=0.89\right.$ & Metering (Volts) $\quad: 13800$ \\
\hline $\mathrm{KVArh}_{\mathrm{L}}=468704$ & Test Period LF = Active engy/(Max active PWR $\left.{ }^{*} \mathrm{His}\right)=0.66$ & AV. (Kw) [ excl. low KW]: 5892 \\
\hline KVArh $_{C}=0$ & Rel. WD SPP LF $=$ SPP Aver. KW/Max KW $=0.82$ & S/S MD \\
\hline
\end{tabular}
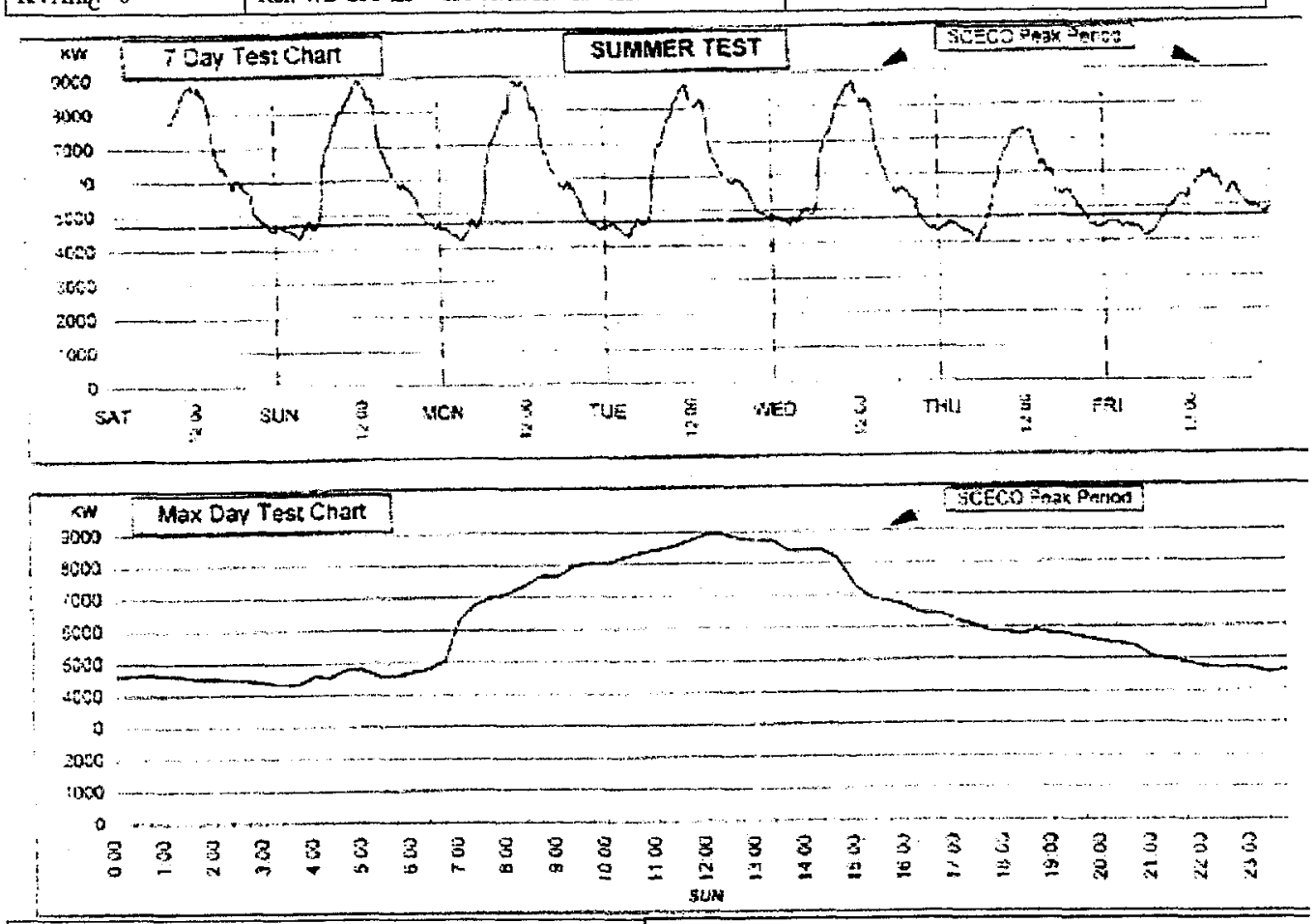

\begin{tabular}{|c|c|c|c|c|c|c|c|c|c|c|c|c|}
\hline \multicolumn{10}{|c|}{ Work cycle } & \multicolumn{3}{|c|}{ Comments \& Recommendations: } \\
\hline & \multicolumn{3}{|c|}{ Cycle 1} & \multicolumn{3}{|c|}{ Cycie 2} & \multirow{2}{*}{$\begin{array}{l}\text { Wrk } \\
\text { FIRS }\end{array}$} & \multirow{2}{*}{$\begin{array}{l}\text { SPP } \\
\text { HRS }\end{array}$} & \multirow{2}{*}{$\begin{array}{l}\text { Cyc- } \\
\text { les }\end{array}$} & \multirow{8}{*}{$\begin{array}{l}\text { PF: } 0.89 \\
\text { Voltage : } \\
\text { TP. LF : } \\
\text { R. LF : } \\
\text { SPP : } \\
\text { Base load : } \\
\text { Work cycle : } \\
\text { Tests : } \\
\text { Other : }\end{array}$} & \multirow{3}{*}{$\begin{array}{l}\text {,FAIR; improve to }(0.95) \\
\text { OK }\end{array}$} & \\
\hline & Wu & WD & HRS & WU & WD & HRS & & & & & & \\
\hline \multicolumn{10}{|l|}{ Sat } & & & \\
\hline \multicolumn{10}{|l|}{ Sun } & & & \\
\hline \multicolumn{10}{|c|}{ Mon } & & & \\
\hline \multicolumn{10}{|l|}{ Tue } & & & \\
\hline \multicolumn{10}{|c|}{ Wed } & & & \\
\hline \multicolumn{10}{|l|}{ Thu } & & & \\
\hline Fri & & & & & & & & & & \multirow[b]{2}{*}{ Potential SPP MAX save : } & & \\
\hline & & & & & & & & & & & KW & $\operatorname{sun} 29-08-99 \quad 11: 22$ \\
\hline
\end{tabular}




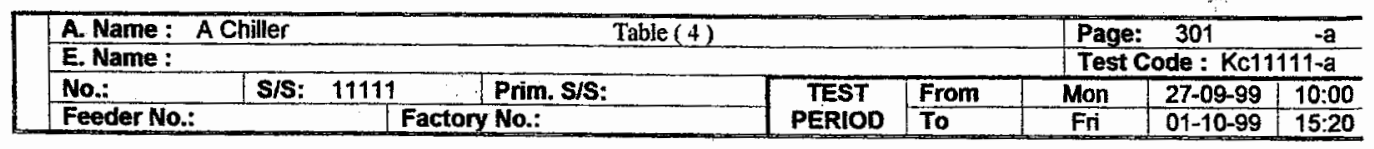

\begin{tabular}{|l|c|c|c|c|c|c|c|c|}
\hline \multicolumn{1}{|c|}{ Reading } & MAX & Day & Date & Time & MIN & Day & Date & Time \\
\hline Active Power (KW) & 78 & MON & $27-09-99$ & $15: 20$ & 0 & MON & $27-09-99$ & $19: 40$ \\
\hline Reactive Power (KVAr) & 47 & WED & $29-09-99$ & $19: 20$ & 0 & MON & $27-09-99$ & $19: 40$ \\
\hline Volks (V) $(119<$ V $<135\}$ & 130 & TUE & $28-09-99$ & $13: 40$ & 122 & MON & $27-09-99$ & $12: 00$ \\
\hline Power Factor & 0.88 & MON & $27-09-99$ & $10: 20$ & 0.83 & WED & $29-09-99$ & $2: 20$ \\
\hline
\end{tabular}

\begin{tabular}{|c|c|c|}
\hline KWh $=1466$ & Average $\mathrm{PF}=\cos \left(\tan ^{-1}(\mathrm{KVArh} / \mathrm{KW} / \mathrm{h})=0.85\right.$ & Metering (Volts) \\
\hline KVATh $_{L}=904$ & Test Period LF = Active engy/(Max active PWR $*$ Hrs) $=0.19$ & AV. $(\mathrm{KW})[$ excl. low KW $]: 61$ \\
\hline KVArth $=0$ & Rel. WD SPP LF $=$ SPP Aver. KWMax KW $=0.55$ & $\mathrm{~S} / \mathrm{S} \mathrm{MD}$ \\
\hline
\end{tabular}
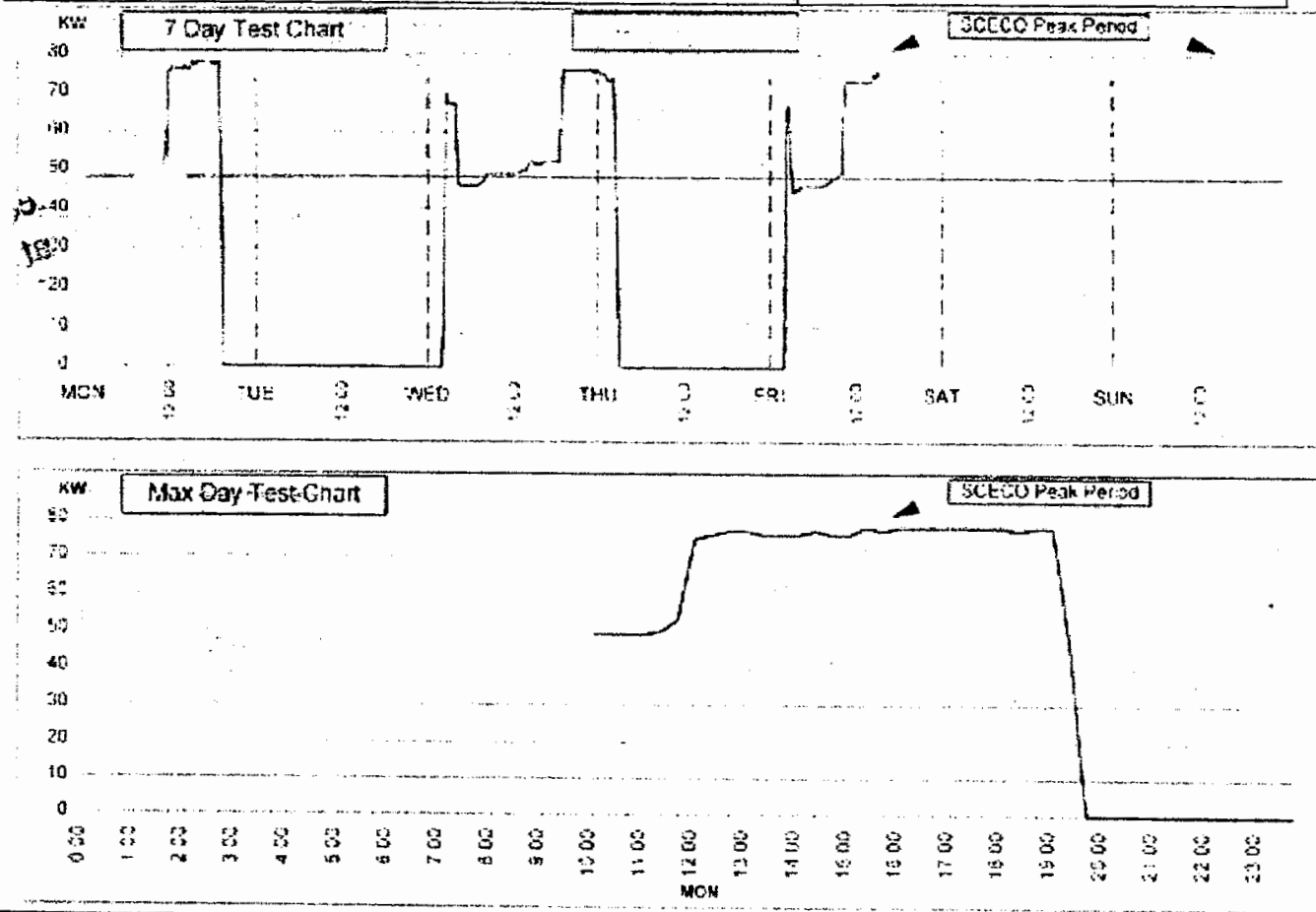

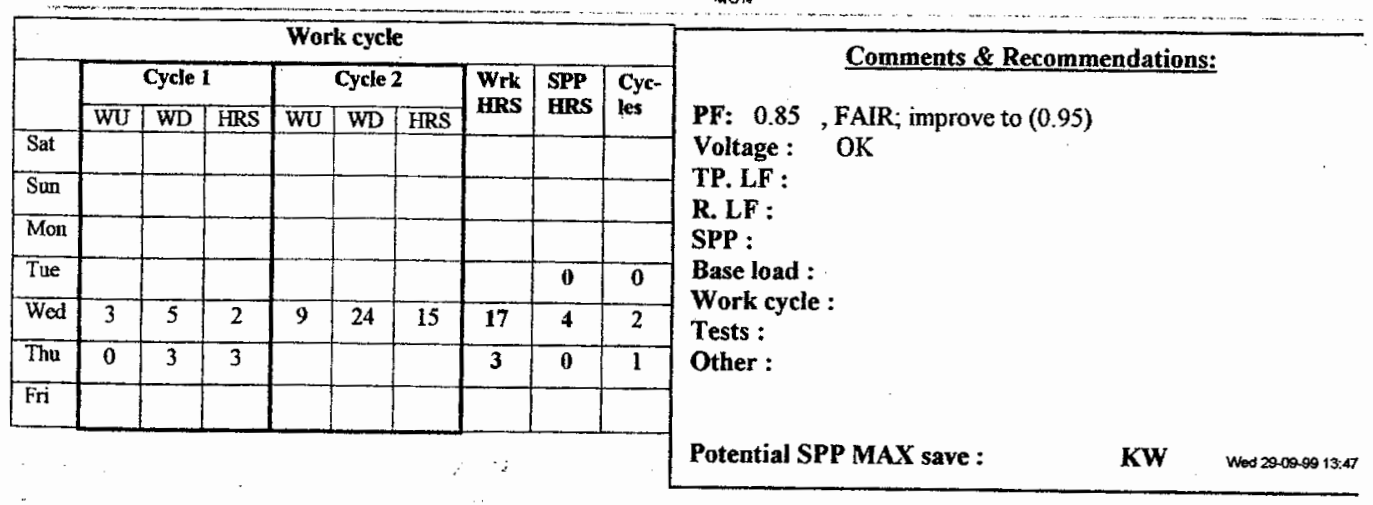




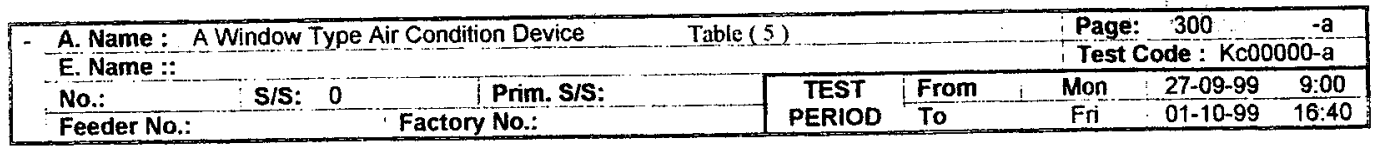

\begin{tabular}{|l|c|c|c|c|c|c|c|c|}
\hline \multicolumn{1}{|c|}{ Reading } & MAX & Day & Date & Time & MIN & Day & Date & Time \\
\hline Active Power (KW) & 2621 & WED & $29-09-99$ & $18: 40$ & 0 & MON & $27-(19-99$ & $20: 40$ \\
\hline Reactive Power (KVAr) & 666 & WED & $29-(19-99$ & $17: 20$ & 0 & MON & $27-09-99$ & $20: 40$ \\
\hline Volts (V) $1119<$ V $135:$ & 74 & TUE & $28-(199-99$ & $5:(6)$ & 53 & WED & $29-(19-99$ & $17: 00$ \\
\hline Power Factor & 0.98 & WED & $29-(19-99$ & $18: 20$ & 0.84 & WED & $29-499-99$ & $9: 00$ \\
\hline
\end{tabular}

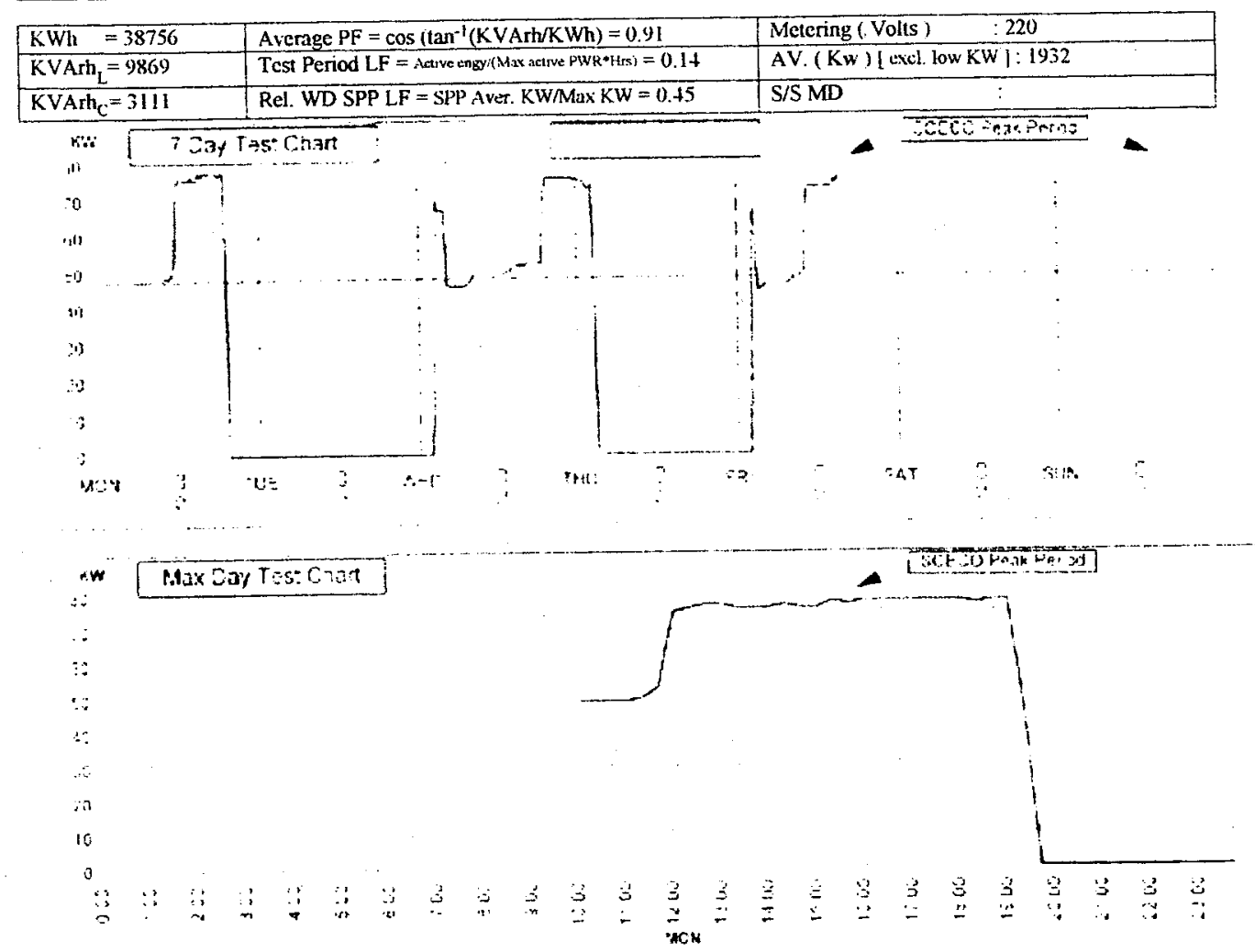

\begin{tabular}{|c|c|c|c|c|c|c|c|c|c|c|}
\hline \multicolumn{8}{|c|}{ Work cycle } & \multicolumn{3}{|c|}{ Comments \& Recommendations: } \\
\hline & \multicolumn{3}{|c|}{ Cycle I } & Cycle 2 & Wrk & SPP & Cyc- & \multirow{3}{*}{\multicolumn{3}{|c|}{$\begin{array}{l}\text { PF: } 0.91 \text {. SATISFACTORY }<<\text { PF correction expected } ">> \\
\text { Voltage: } \quad \text { LOW VOLTAGE (report to distret!!!) }\end{array}$}} \\
\hline & Wij & WD & IRS & WU WO IRS & & & & & & \\
\hline \multicolumn{8}{|c|}{ and } & & & \\
\hline \multicolumn{8}{|l|}{$\operatorname{Sun}$} & \multirow{7}{*}{$\begin{array}{l}\text { TP. LF : } \\
\text { R. LF : } \\
\text { SPP : } \\
\text { Base load : } \\
\text { Work cycle : } \\
\text { Tests : } \\
\text { Other : } \\
\text { Potential SPP MAX save : }\end{array}$} & & \\
\hline \multicolumn{8}{|c|}{ Mon } & & & \\
\hline \multicolumn{8}{|l|}{ Tuc } & & & \\
\hline \multicolumn{8}{|c|}{ Wed } & & & \\
\hline \multicolumn{8}{|l|}{ Thu } & & & \\
\hline \multicolumn{8}{|l|}{ in } & & & \\
\hline & & & & & & & & & KW & Wed $2909-99134$ \\
\hline
\end{tabular}


تأثير التوافقيات الكهربائية على كفاءة استهلاك الطاقة لأجهزة التكييف

د، عمر بن محمد باسسودان د د ياسر حجازى

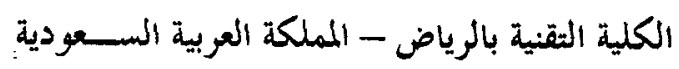

\section{ملخص البحث}

تكثل التو افقيات التي تبعثها الأجهزة المختلفة عبئًا على النظام الكهر بائي. و تعتــبر الزيسـادة في قيمسـة

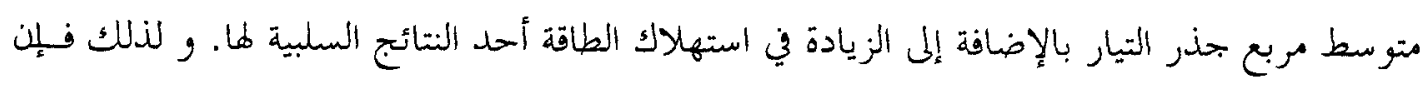

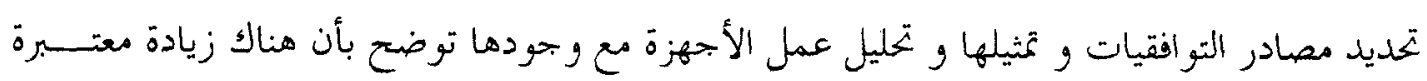

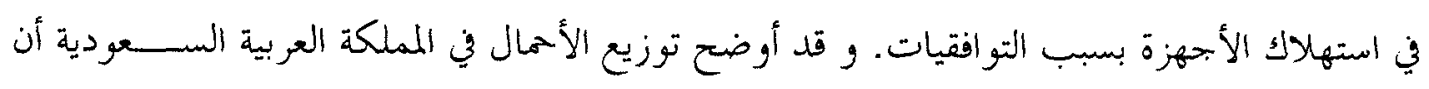

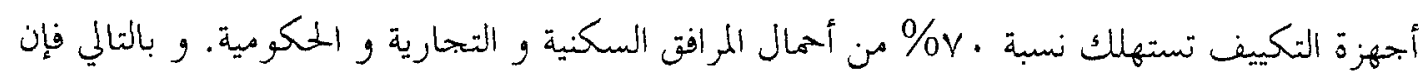

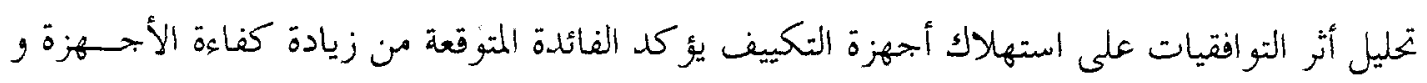

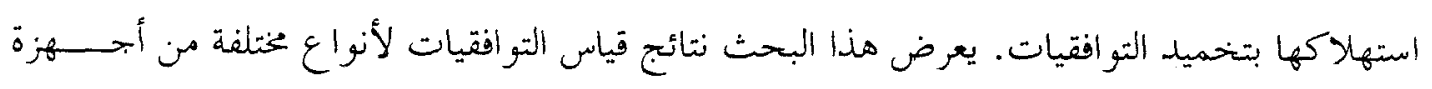

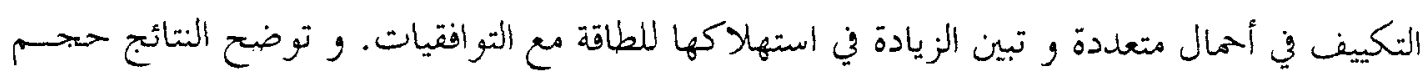
التو افقيات و أثر ها على كفاءة استهلاك الأجهزةة. 